\title{
WORKSHOP PENELITIAN TINDAKAN KELAS BAGI GURU-GURU DI YAYASAN DARUL ULUM KARANGPANDAN PASURUAN
}

\author{
Umi Hanifah, Mayang Sari, Firda Hariyanti, Dwi Hidayanti \\ Institut Teknologi dan Sains Nahdlatul Ulama Pasuruan \\ Email: umihanifah@itsnupasuruan.ac.id
}

\begin{abstract}
Abstrak:
Tujuan workshop ini pada khususnya diharapkan dapat meningkatkan atau memperbaiki kinerja belajar siswa di sekolah, meningkatkan mutu proses pembelajaran di kelas, meningkatkan kualitas penggunaan media, alat bantu belajar, dan sumber belajar lainnya, meningkatkan, memperbaiki maupun menjaga kualitas prosedur dan alat evaluasi yang digunakan untuk mengukur proses dan hasil belajar siswa. Selain itu, workshop ini juga dimaksudkan untuk membantu guru-guru dalam upaya peningkatan atau perbaikan terhadap masalah-masalah pendidikan anak di sekolah serta peningkatan dan perbaikan terhadap kualitas penerapan kurikulum dan pengembangan kompetensi siswa di sekolah. Metode yang digunakan dalam pelaksanaan pelatihan ini adalah metode ceramah, latihan, dan evaluasi. Secara umum, hasil pelaksanaan pengabdian pada masyarakat ini adalah cukup baik dan reponsif (dari rata-rata respons peserta pasca pelatihan sebesar $80,45 \%$ yang berada pada kategori positif) artinya terdapat pemahaman para guru tentang profesinya, terutama dalam hal pemahaman penulisan/ pembuatan/ pelaksanaan Penelitian Tindakan Kelas.
\end{abstract}

Kata Kunci: Penelitian Tindakan Kelas, Pembelajaran Siswa

\begin{abstract}
:
The purpose of this workshop is in particular expected to be able to improve or improve student learning performance in schools, improve the quality of classroom learning processes, improve the quality of media use, learning aids, and other learning resources, improve, improve and maintain the quality of procedures and evaluation tools used to measuring the process and results of student learning. In addition, this workshop is also intended to assist teachers in efforts to improve or improve the problems of child education in schools and improve and improve the quality of curriculum implementation and the development of student competencies in schools. The method used in the implementation of this training is the method of lecture, practice, and evaluation. In general, the results of the implementation of community service are quite good and responsive (from the average response of participants after training at $80.45 \%$ which is in the positive category) meaning that there is an understanding of the teachers about their profession, especially in terms of understanding writing/making/implementation of Classroom Action Research.
\end{abstract}

Keywords: Classroom Action Research, Student Learning 


\section{Pendahuluan}

Pendidikan mempunyai inti terjadinya interaksi antara pendidik dan peserta didik dalam membantu peserta didik menguasai tujuan-tujuan pendidikan. Interaksi pendidikan dapat berlangsung di lingkungan keluarga, sekolah, dan masyarakat, dimana akan mendukung peserta didik mengembangkan pengalaman pendidikannya. Sistem Pendidikan Nasional menyatakan bahwa pendidikan merupakan usaha sadar untuk mempersiapkan peserta didik melalui kegiatan bimbingan, pengajaran, dan atau latihan ${ }^{1}$. Untuk mendukung peningkatan pendidikan di Indonesia, guru dituntut memiliki beberapa kompetensi.

Profesi guru sebagai agen pembelajaran mensyaratkan 4 (empat) kompetensi, yaitu kompetensi pedagogik, kepribadian, sosial, dan professional ${ }^{2}$. Kompetensi profesional merupakan kemampuan penguasaan materi pelajaran secara luas dan mendalam. Salah satu upaya yang dapat dilakukan guru profesional untuk meningkatkan kualitas pembelajaran adalah melalui penelitian tindakan kelas (PTK). PTK merupakan pencermatan terhadap kegiatan belajar berupa sebuah tindakan, yang sengaja dimunculkan dan terjadi dalam sebuah kelas secara bersama ${ }^{3}$. Dalam PTK dikembangkan berbagai model pembelajaran yang dipakai sebagai salah satu variabel untuk meningkatkan kualitas pembelajaran. Melalui PTK permasalahan pendidikan dan pembelajaran dapat dikaji, ditingkatkan, dan dituntaskan, sehingga proses pendidikan dan pembelajaran berlangsung secara inovatif serta memperoleh hasil belajar yang lebih baik ${ }^{4}$.

Permasalahan yang dihadapi guru-guru Yayasan Darul Ulum Karangpandan Pasuruan di Kabupaten Pasuruan terkait PTK adalah keengganan guru melaksanakan PTK, implementasi PTK belum sesuai harapan, dan guru mengalami kendala dalam penulisan laporan PTK yang telah dilakukan. Berdasarkan uraian tersebut, mendorong Tim Pengabdi dari Prodi Pendidikan Matematika ITSNU Pasuruan untuk membantu memfasilitasi upaya peningkatan profesionalisme guru melalui pemberian materi PTK serta penyusunan proposal dan laporan PTK.

\section{Penelitian Tindakan Kelas (PTK)}

Pengertian PTK atau action research telah mulai berkembang sejak perang dunia kedua. Akibatnya, terdapat banyak sekali definisi-definisi yang satu dengan lainnya sangat mirip. Salah satu definisi tersebut adalah yang dikemukakan oleh McNiff bahwa, "action research is a form of self-reflective inquiry undertaken by perticipants (teacher, students or principals, for example) in social (incluiding educational) situation in order to improve the rationality and justice of (1) their own social or educational practices, (2) their understanding of these practices, and the

\footnotetext{
${ }^{1}$ Depdiknas. Undang-undang RI No.20 Tahun 2003 Tentang Sistem Pendidikan Nasional. (Jakarta: Depdiknas, 2003)

${ }^{2}$ Depdiknas. Undang-Undang Republik Indonesia No. 14 Tahun 2005 tentang Guru dan Dosen. (Jakarta: Depdiknas, 2005)

${ }^{3}$ Suharsimi Arikunto, Suhardjono, dan Supardi. Penelitian Tindakan Kelas. (Jakarta: Bumi Aksara, 2008), 3.

${ }^{4}$ Sefna Rismen, Hafizah Delyana, Audra Paramitha M, Melisa dan Mulia Suryani, Workshop Pelaksanaan Penelitian Tindakan Kelas Pada Musyawarah Guru Mata Pelajaran (MGMP) Matematika Kota Solok, Sumatera Barat. (Empowerment: Jurnal Pengabdian Masyarakat. Vol 1, No 1, 2018), 6065
} 
situations in which the practices are carried out. " 5

Berdasarkan pendapat tersebut, kita dapat mencermati pengertian PTK secara lebih rinci dan lengkap. Secara singkat PTK dapat didefinisikan bahwa penelitian tindakan merupakan penelitian dalam bidang sosial, yang menggunakan refleksi diri sebagai metode utama, dilakukan oleh orang yang terlibat di dalamnya, serta bertujuan untuk melakukan perbaikan dalam berbagai aspek.

\section{Metode Penelitian}

Agar tujuan tercapai, kegiatan pelatihan PTK ini dilakukan dengan pendampingan agar dapat berjalan dengan lancar maka sebagai alternatif pemecahan masalah adalah sebagai berikut: pendampingan dilakukan dengan pendekatan individual dan klasikal. Pendekatan klasikal dilakukan pada saat pemberian teori tentang cakupan penelitian kelas dan pendekatan individual dilakukan pada saat latihan membuat proposal PTK.

Metode pelaksanaan yang digunakan adalah metode ceramah, Metode ini dipilih untuk menyampaikan konsep-konsep yang penting untuk dimengerti dan dikuasai oleh peserta pelatihan. Materi yang diberikan meliputi topik dan langkahlangkah penelitian tindakan kelas. Kedua Latihan, metode ini digunakan untuk memberikan tugas kepada peserta pendampingan untuk mempraktikkan pembuatan proposal PTK. Ketiga, evaluasi setelah dilakukan pendampingan kepada para peserta, maka dilakukan penilaian atau evaluasi terhadap karya peserta mengenai masalah PTK dan langkah-langkah PTK.

1. Materi Pelatihan
a. Konsep Dasar dan Prinsip PTK
b. Model-model PTK
c. Penyusunan Laporan PTK

2. Tahapan Kegiatan PKM
a. Persiapan Sosialisasi Program
b. Koordinasi dengan mitra PkM
c. Penyusunan konsep kegiatan PkM
d. Penyusunan proposal PkM
e. Pelaksanaan Kegiatan PkM
f. Penyusunan draf laporan PkM

\section{Teknik Analisis Data}

Analisis respons peserta terhadap kegiatan workshop dihitung dengan melihat jawaban peserta terhadap penyataan yang diajukan pada angket respons. Pilihan jawaban pada angket yaitu, sangat setuju (SS), setuju (S), kurang setuju (KS), dan tidak setuju (TS). Angket respons peserta workshop hanya terdiri dari pernyataan positif (favorable).

Tabel 1 Pedoman Penskoran Angket Respons

\begin{tabular}{cc}
\hline Kategori Jawaban & Skor Pilihan Jawaban \\
\hline TS & 1 \\
\hline KS & 2 \\
\hline
\end{tabular}

\footnotetext{
${ }^{5}$ McNiff, J. Action Research: Principles and Practice, (New York: Routledge, 1988)
} 


\begin{tabular}{cl}
\hline S & 3 \\
\hline SS & 4 \\
\hline
\end{tabular}

Langkah-langkah dalam menganalisis data respons peserta ${ }^{6}$ yaitu:

1. Menghitung Nilai Respons Peserta

$$
N R=\sum(B R \times S)
$$

Keterangan:

NR : Nilai Respons Guru

BR : Banyak pilihan jawaban

S : Skor pilihan jawaban

2. Menentukan Persentase Rata-rata Skor Respons

Keterangan:

$$
P \%=\frac{N R}{\text { skor maksimal }} \times 100 \%
$$

$\mathrm{P} \% \quad$ : Persentase rata-rata skor respons

NR : Nilai Respons Guru

3. Menentukan Kategori Respons Peserta

Menentukan kategori respons peserta terhadap suatu butir pernyataan dengan cara mencocokkan hasil persentase rata-rata skor tiap butir pernyataan dengan kategori di bawah ini:

Tabel 2 Pedoman Kategori Respons Peserta

\begin{tabular}{ccc}
\hline No & $\begin{array}{c}\text { Persentase rata-rata skor respons } \\
(\mathbf{\% )}\end{array}$ & Kategori \\
\hline 1. & $\mathrm{Rs} \geq 85$ & sangat positif \\
\hline 2. & $70 \leq \mathrm{Rs}<85$ & positif \\
\hline 3. & $50 \leq \mathrm{Rs}<70$ & kurang positif \\
\hline 4. & $\mathrm{Rs}<50$ & tidak positif \\
\hline
\end{tabular}

\section{Pembahasan dan Hasil Penelitian}

Pelaksanaan workshop Penelitian Tindakan Kelas (PTK) telah dilaksanakan pada tanggal 23 Maret 2019 di MA Darul Ulum Karangpandan Pasuruan. Sebelum penjelasan materi tentang PTK, guru-guru diberi kesempatan untuk mengisi angket respon guru pra pelatihan. 28 peserta ambil bagian dalam pengisian angket ini. Angket ini bertujuan untuk melihat latar belakang peserta workshop berkaitan dengan materi yang disampaikan. Hasil angket respons pra pelatihan seperti pada Tabel 3 berikut.

Tabel 3 Hasil Angket Repons Guru Pra Pelatihan

6 Siti Khabibah, "Pengembangan Model Pembelajaran Matematika dengan Soal Terbuka untuk Meningkatkan Kreativitas Siswa Sekolah Dasar," (Surabaya: Disertasi Universitas Negeri Surabaya, 2006), 90 


\begin{tabular}{|l|l|l|l|l|l|}
\hline No & Pernyataan & BR & NR & P (\%) & K \\
\hline 1 & $\begin{array}{l}\text { Penelitian Tindakan Kelas (PTK) } \\
\text { masih diperlukan oleh guru. }\end{array}$ & 28 & 101 & 90.18 & $\begin{array}{l}\text { Sangat } \\
\text { Positif }\end{array}$ \\
\hline 2 & $\begin{array}{l}\text { Saya masih banyak mengalami } \\
\text { kesulian dalam melaksanakan PTK }\end{array}$ & 28 & 92 & 82.14 & Positif \\
\hline 3 & Kesulitan yang saya alami adalah: & & & & \\
\hline & Menentukan judul & 28 & 76 & 67.86 & Negatif \\
\hline & Membuat latar belakang & 28 & 78 & 69.64 & Negatif \\
\hline & Menentukan masalah penelitian & 28 & 79 & 70.54 & Positif \\
\hline & Membuat kajian teori & 28 & 80 & 71.43 & Positif \\
\hline & Membuat instrumen penelitian & 28 & 80 & 71.43 & Positif \\
\hline & Menganalisis data & 28 & 81 & 72.32 & Positif \\
\hline & Membuat laporan PTK & 28 & 80 & 71.43 & Positif \\
\hline & Membuat artikel PTK & 28 & 77 & 68.75 & Negatif \\
\hline 4 & $\begin{array}{l}\text { Sertifikasi guru dipersyaratkan } \\
\text { membuat laporan PTK }\end{array}$ & 28 & 82 & 73.21 & Positif \\
\hline
\end{tabular}

Selain data pada Tabel 3, hasil angket juga menunjukkan bahwa dari 28 peserta yang mengisi angket, $42,86 \%$ menjawab pernah membuat PTK. Dari persentase tersebut, 28,57\% menghasilkan 1 buah PTK, 7,14\% menghasilkan 2 buah PTK, dan 7,14\% menghasilkan lebih dari 2 buah PTK. Setelah penjelasan materi, para peserta diberi kesempatan untuk mengisi angket berkaitan dengan workshop yang telah dilakukan. Hasil angket respons pasca pelatihan seperti pada Tabel 4 berikut.

Tabel 4 Hasil Angket Repons Guru Pasca Pelatihan

\begin{tabular}{|c|l|c|c|c|c|}
\hline No & \multicolumn{1}{|c|}{ Pernyataan } & BR & S & P(\%) & K \\
\hline 1 & $\begin{array}{l}\text { Workshop ini membantu saya memahami } \\
\text { bagaimana seharusnya mengembangkan } \\
\text { penelitian tindakan kelas (PTK) }\end{array}$ & 28 & 93 & 83.04 & Positif \\
\hline 2 & $\begin{array}{l}\text { Materi workshop ini memberikan } \\
\text { pengetahuan dari pengalaman pada saya } \\
\text { bagaimana membuat proposal PTK }\end{array}$ & 28 & 90 & 80.36 & Positif \\
\hline 3 & $\begin{array}{l}\text { Workshop ini memberikan pengalaman pada } \\
\text { saya bagaimana melaksanakan PTK }\end{array}$ & 29 & 92 & 82.14 & Positif \\
\hline 4 & $\begin{array}{l}\text { Workshop ini menginspirasi saya untuk } \\
\text { melaksanakan PTK }\end{array}$ & 28 & 87 & 77.68 & Positif \\
\hline 5 & $\begin{array}{l}\text { Workshop ini menumbuhkan keyaknan pada } \\
\text { saya bahwa PTK dapat saya laksanakan } \\
\text { dengan baik }\end{array}$ & 28 & 92 & 82.14 & Positif \\
\hline 6 & $\begin{array}{l}\text { Workshop ini menumbuhkan keyaknan pada } \\
\text { saya bahwa PTK dapat meningkatkan kinerja } \\
\text { saya sebagai guru }\end{array}$ & 28 & 95 & 84.82 & Positif \\
\hline 7 & $\begin{array}{l}\text { Workshop ini membantu saya meningkatkan } \\
\text { kemampuan menulis artikel dengan baik }\end{array}$ & 28 & 89 & 79.46 & Positif \\
\hline
\end{tabular}




\begin{tabular}{|c|l|c|c|c|c|}
\hline No & \multicolumn{1}{|c|}{ Pernyataan } & BR & S & P(\%) & K \\
\hline 8 & $\begin{array}{l}\text { Workshop secara umum bermanfaat dan } \\
\text { dapat dilanjutkan pada tahun berikutnya }\end{array}$ & 28 & 93 & 83.04 & Positif \\
\hline 9 & $\begin{array}{l}\text { Pemateri telah memberikan materi dengan } \\
\text { jelas dan menginspirasi }\end{array}$ & 28 & 86 & 76.79 & Positif \\
\hline 10 & $\begin{array}{l}\text { Perlengkapan materi dan bahan-bahan } \\
\text { workshop sudah memuaskan }\end{array}$ & 28 & 84 & 75.00 & Positif \\
\hline \multicolumn{2}{|l}{ Rata-rata Respons Peserta Pasca Pelatihan } & 80.45 & Positif \\
\hline
\end{tabular}

Secara umum, hasil pelaksanaan pengabdian pada masyarakat ini adalah cukup baik dan reponsif (dari rata-rata respons peserta pasca pelatihan sebesar $80,45 \%$ yang berada pada kategori positif) artinya terdapat pemahaman para guru tentang profesinya, terutama dalam hal pemahaman penulisan/ pembuatan/ pelaksanaan PTK. Para guru yayasan Darul Ulum Karangpandan Pasuruan sangat tertarik untuk meningkatkan profesinya. Pernyataan ini didukung oleh antusiasnya para guru dalam mengikuti dan mengajukan pertanyaan selama pelaksanaan kegiatan pengabdian pada masyarakat. Berkaitan dengan hal tersebut, para guru mempunyai kehendak untuk melakukan penelitian dalam rangka meningkatkan kualitas pembelajaran. Guru profesional menurut Suyanto ${ }^{7}$ perlu melihat dan menilai sendiri secara kritis terhadap praktek pembelajarannya di kelas. Dengan melihat unjuk kerjanya sendiri, kemudian direfleksikan, lalu diperbaiki guru akhirnya akan mendapatkan otonomi secara profesional. Konsep penting dalam pendidikan yaitu selalu adanya upaya perbaikan dari waktu ke waktu pada proses pemebalajarnnya. Hal ini terjadi karena guru mau melakukan penelitian tindakan kelas untuk meningkatkan profesionalismenya.

Guru perlu menjadi peneliti untuk mengetahui apa penyebab munculnya masalah. Sekurang-kurangnya lima manfaat penelitian tindakan kelas menurut Fraenkel, etc ${ }^{8}$ yaitu sebagai berikut 1) PTK dapat dilakukan oleh hampir semua ahli di semua tipe sekolah, semua level, guru kelas baik secara individu maupun berkelompok, ataupun pimpinan sekolah; 2) PTK membantu guru mengidentifkasi masalah-masalah dan isu-isu secara sistematis; 3) PTK memberikan ruang kepada para guru atau praktisi lainnya untuk mengadakan penelitian mereka sendiri sehingga guru dapat mengembangkan cara yang lebih efektif untuk mempraktikkan keahlian mereka; 4) PTK dapat memperbaiki praktik pendidikan; membantu praktisi pendidikan (guru, pimpinan sekolah) dalam meningkatkan kompetensi terhadap apa yang mereka lakukan; dan 5) PTK dapat membangun sebuah komunitas yang berorientasi penelitian ilmiah di dalam sekolah itu sendiri.

\section{Penutup}

Hasil kegiatan workshop ini dapat membantu peserta dalam memahami bagaimana seharusnya mengembangkan PTK, berkaitan dengan materinya memberikan pengetahuan dan pengalaman pada peserta bagaimana membuat

\footnotetext{
${ }^{7}$ Suyanto. Mahir Melakukan Penelitian Tindakan Kelas. (Bandung: Yapindo Press, 1993)

${ }^{8}$ Fraenkel, J. R., How to Design and Evaluate Research in Education (8th). (New York: Mc Graw-Hill Companies, inc, 2012)
} 
proposal dan bagaimana melaksanakannya. Dengan demikian peserta dapat meningkatkan kualitas pembelajaran di kelas; mengembangkan pengetahuan dan keterampilan; secara jujur dan teliti mengungkap hasil penelitian yang sebenarnya agar dapat menjadi suatu pengetahuan yang berguna. Workshop ini juga dapat menginspirasi, menumbuhkan keyakinan peserta bahwa PTK dapat dilaksanakan dan dapat meningkatkan kinerja.

\section{Daftar Pustaka}

Arikunto, Suharsimi. Suhardjono, dan Supardi. Penelitian Tindakan Kelas. (Jakarta: Bumi Aksara, 2008)

Depdiknas. Undang-Undang Republik Indonesia No. 14 Tahun 2005 tentang Guru dan Dosen. (Jakarta: Depdiknas, 2005)

Depdiknas. Undang-undang RI No.20 Tahun 2003 Tentang Sistem Pendidikan Nasional. (Jakarta: Depdiknas, 2003)

Fraenkel, J. R., How to Design and Evaluate Research in Education (8th). (New York: Mc Graw-Hill Companies, inc, 2012)

Khabibah, Siti. "Pengembangan Model Pembelajaran Matematika dengan Soal Terbuka untuk Meningkatkan Kreativitas Siswa Sekolah Dasar," (Surabaya: Disertasi Universitas Negeri Surabaya, 2006)

McNiff, J. Action Research: Principles and Practice, (New York: Routledge, 1988)

Rismen, Sefna. Hafizah Delyana, Audra Paramitha M, Melisa dan Mulia Suryani, Workshop Pelaksanaan Penelitian Tindakan Kelas Pada Musyawarah Guru Mata Pelajaran (MGMP) Matematika Kota Solok, Sumatera Barat. (Empowerment: Jurnal Pengabdian Masyarakat. Vol 1, No 1, 2018)

Suyanto. Mahir Melakukan Penelitian Tindakan Kelas. (Bandung: Yapindo Press, 1993) 